\title{
The Effect of Current Harmonic on Overcurrent Relay
}

\author{
Muhammad Hafiz Mohd Rohaizad, Syafrudin Masri and Noramalina Abdullah* \\ School of Electrical and Electronic Engineering, Universiti Sains Malaysia, \\ Engineering Campus, 14300 Nibong Tebal, Pulau Pinang, Malaysia
}

"Corresponding author: eenora@usm.my

Published online: 30 June 2020

To cite this article: Muhammad Hafiz Mohd Rohaizad, Syafrudin Masri and Noramalina Abdullah (2020). The effect of current harmonic on overcurrent relay. Journal of Engineering Science, 16(1), 65-74, https://doi.org/10.21315/jes2020.16.1.5.

To link to this article: https://doi.org/10.21315/jes2020.16.1.5

\begin{abstract}
Overcurrent relay is an important protective device for protection in power system. It can clear the large fault current quickly and easily coordinate with circuit breaker. The maximum load current that an equipment can endure during continuous operation may also have a fault and various disturbance. This condition will lead to overcurrent and malfunction equipment. The variety of loads also will influence the sinusoidal waveform, which comes out from harmonic distortion. This article investigated the effects of current harmonic on overcurrent relay. The performance of overcurrent relay is analysed with laboratory experiment. The laboratory experiment that consists of non-linear load current which have different total harmonic distortion (THD) to obtain such results. It can be concluded that a relay malfunction will occur and they will trip in a wrong sequence when affected by harmonic. The higher number of THD, the tripping current also getting higher.
\end{abstract}

Keywords: overcurrent, power system, harmonic distortion, circuit breaker, relay malfunction

\section{INTRODUCTION}

The electrical equipment ability to consume the energy being supplied to it is referred to power quality. Power equality problems in electric power system due to injected harmonics current. Nowadays, power quality problem in power utility distribution is not a new thing. Harmonic currents or voltages are generated from a non-linear load when it is connected to the main supply since harmonic exist in a system wide spread problem today and may malfunction the equipment. Most of the literature reveal that the performance of relays in presence of harmonics is not significantly affected when total harmonic distortion (THD) is less than $20 \%{ }^{1}$ 
The article "Impact of Harmonics on the Performance of Over-Current Relays" written by Hillary Tin, A. Abu-Siada and M. S. Masoum conclude that by simulation result show, when THD is more than $20 \%$ the over current relay's performance will be significantly effected and a malfunction will be caused. When a fault occurs in the system, the over current relay will not be able to isolate the faulty location as they will trip in an undesired way. ${ }^{2}$

Overcurrent relays are frequently used in power network systems because most of the faulty conditions generally increases beyond its design limits. ${ }^{3}$ So, in most of the common faults, overcurrent relays play their role and provide the signal to the circuit breaker to isolate the faulty line from the remaining system. ${ }^{4}$ The inverse time overcurrent relay is one of a type of overcurrent relays which is a natural character of any induction type rotating device. Here, the speed of rotation of rotating part of the device is faster if the input has more current. In other words, time of operation inversely varies with input current. This natural characteristic of relay is very suitable for overcurrent protection. If the fault is severe, it will clear the fault faster. ${ }^{5}$ Hence, in this research, inverse time over current relay (ITOCR) will be used and the time will be ignored.

\section{RELATED WORK}

The power quality problem involves considerations of the harmonic from the system which come from non-linear loads. A non-linear load may lead to malfunction equipment and machine or failure in the presence of high harmonic current levels. Harmonic distortion has become a growing concern for facility managers, users of automation equipments and engineers. ${ }^{6}$ For this research, inverse time overcurrent relay was used to determine the performance on effect of harmonic. This characteristic can be achieved by different THD. The usage of non-linear load can be adjust by using a rheostat and capacitance to reduce the amount of THD. ${ }^{7}$ Rectifier also has been use as non-linear load since the harmonic-related problems caused by the widespread use of large-capacity non-linear loads such as rectifiers, inverters and Cyclo-converters in industries. ${ }^{8}$

THD of a signal is the ratio of the sum of the powers of all harmonic frequencies above the fundamental frequency to the power of the fundamental frequency. For this research, THD was measured by using a power analyser and also known as fluke. Fluke are robust tools capable advanced of energy monetisation to help prepare for any power quality issues and help to discover the state of health of the power system. In order to achieve impact of harmonic on overcurrent relay, current setting was set up to determine whether there was any tripping action occurred within the current setting. 


\subsection{Inverse Time Overcurrent Relay}

The overcurrent relay is defined as the relay, which operates only when the value of the current is greater than the relay setting time. It protects the equipment of the power system from the fault current. The inverse time overcurrent relay operates only when the magnitude of their operating current is inversely proportional to the magnitude of the energise quantities. The operating time of relay decreases with the increases in the current. The operation of the relay depends on the magnitude of the current. ${ }^{9}$

\section{$2.2 \quad$ Non-Linear Load}

A load is said to be non-linear when the current it draws does not have the same waveform as the supply voltage. Non-linear loads connected to an electric power system produce harmonic currents, harmonics are introduced into the system in the form of currents whose frequencies are the integral multiples of the fundamental power system frequency 50 or $60 \mathrm{~Hz} .{ }^{10}$ Examples of non-linear load devices comprising power electronics circuits are typical non-linear loads. Such loads are increasingly frequent and their percentage in overall electrical consumption is growing steadily.

\subsection{THD}

THD is the summation of all harmonic components of the voltage or current waveform compared against the fundamental component of the voltage or current wave: Harmonic is a sinusoidal component of a periodic wave or quantity having a frequency that is integral multiples of the fundamental frequency. ${ }^{11}$ THD can be used to estimate the degree to which a system is non-linear. A THD measurement can be made by applying a sine wave as an input to a system and measuring the total energy which appears at the output of the system at harmonics of the input frequency. ${ }^{12}$ A sinusoidal input is used because sinusoids contain energy at only a single frequency.

\subsection{Harmonics}

Harmonic currents, generated by non-linear electronic loads, increase power system heat losses and power bills of end-users. As the number of harmonics-producing loads have increased over the years, it has become increasingly necessary to address their influence when making any additions or changes to an installation. The first step to solve harmonic related problems is to perform an analysis to determine the specific needs of electrical distribution system. To determine capacitor and filter 
requirements, it is necessary to establish the impedance of the supply network and the value of each harmonic current. ${ }^{13}$

\section{METHODOLOGY}

For the laboratory experiment, the apparatus involved was overcurrent relay, rectifier, capacitor, rheostat, power quality analyser and multimeter. The current setting of overcurrent relay must be set to ensure that the relay will trip at its setting. While rectifier, rheostat and capacitor act as non-linear load. Power quality analyser was used to measured THD for this experiment. The multimeter was used to measure load current.

To achieve different number of THD, non-linear load need to be varied. Different numbers of THD were important for this research to observe the performance of overcurrent relay. Theoretically, rectifier has a large number of harmonic. Hence rectifier must be used. The function of capacitor was to reduce the ripple as well as to vary the number of THD.

Experiment was started by using linear load, which had zero THD. To have a linear load, rectifier and capacitor had been removed from the circuit. Figure 1 shows the circuit when THD was zero:

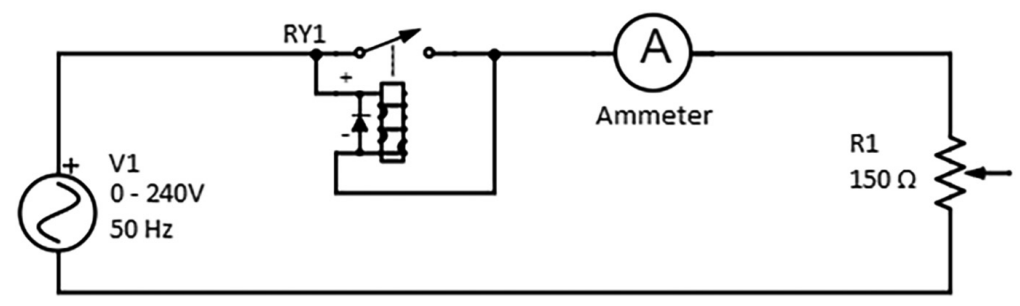

Figure 1: Linear load circuit.

Experiment has been carried on with different number of THD. Circuit for non-linear load as Figure 2. Current rating of each equipment needs to be observed to ensure that circuit can flow smoothly. For this research, current setting was set up and had been fixed. Load current need to be measured by multimeter and data were recorded. Figure 3 shows the flowchart of the project. 


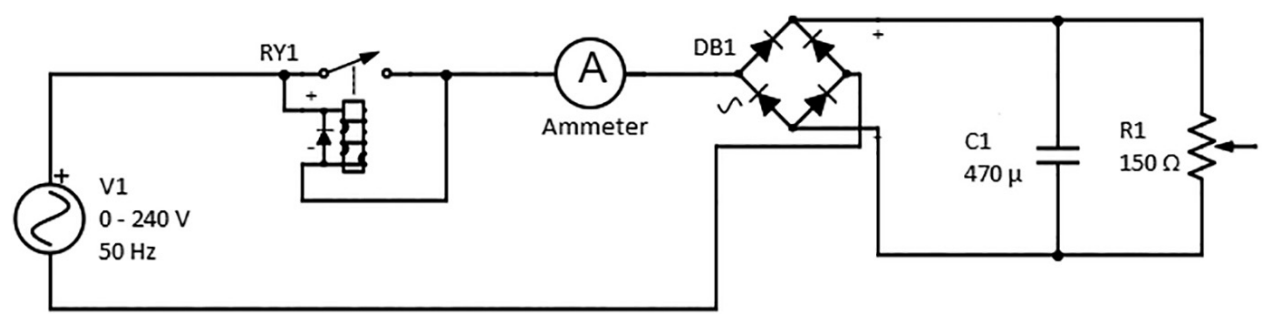

Figure 2: Non-linear load circuit.

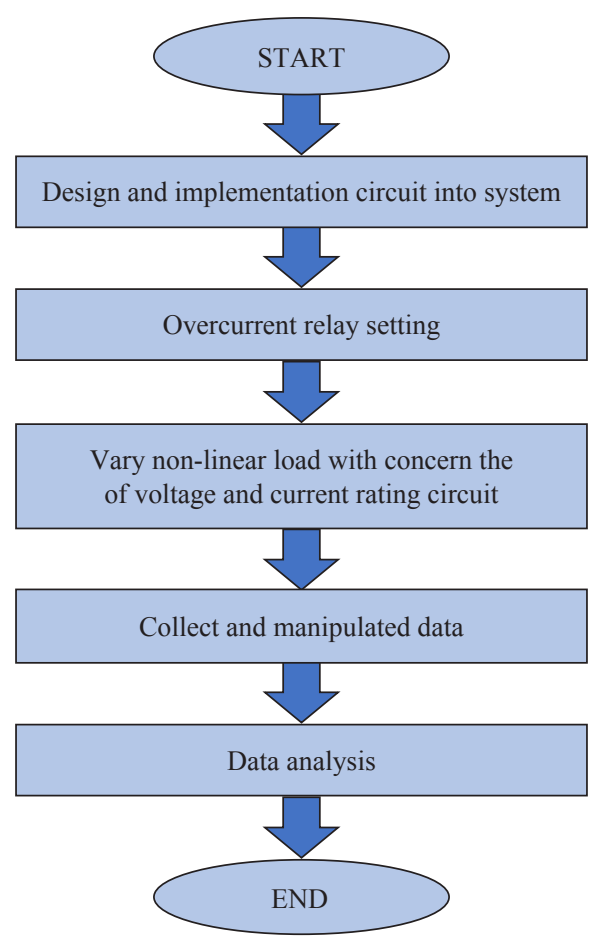

Figure 3: Flowchart of the project.

\section{RESULTS AND DISCUSSION}

In this research, after being tested for 12 times, the final result and the impact of harmonic were analysed. Table 1 shows the result for 12 times test which consists of $0 \%-53 \%$ THD. In order to get reading for the experiment result, the circuit had been set up as in Figure 2. Multimeter which label XMM1 was use to measure load current. For $0 \%$ THD rectifier and capacitor was removed from the circuit as Figure 1. This scematic diagram was built using multisim software. 
Table 1: Result from $0 \%$ to $53.0 \%$ THD.

\begin{tabular}{cccc}
\hline $\mathrm{I}_{\text {load }}(\mathrm{A})$ & $\mathrm{I}_{\text {setting }}(\mathrm{A})$ & THD $(\%)$ & Trip \\
\hline 1.000 & 1.000 & 0 & YES \\
1.021 & 1.000 & 8.1 & YES \\
1.034 & 1.000 & 11.3 & YES \\
1.057 & 1.000 & 15.4 & YES \\
1.061 & 1.000 & 22.2 & YES \\
1.078 & 1.000 & 29.5 & YES \\
1.092 & 1.000 & 34.7 & YES \\
1.104 & 1.000 & 37.0 & YES \\
1.107 & 1.000 & 39.0 & YES \\
1.119 & 1.000 & 42.9 & YES \\
1.174 & 1.000 & 52.0 & YES \\
1.185 & 1.000 & 53.0 & YES \\
\hline
\end{tabular}

The graph in Figure 4 is a scatter plot. Scatter diagram axis is created with tripping current versus THD to observe the impact of harmonic which consist of different value of THD on overcurrent relay to observe either it trips on its setting. Based on Figure 4, the trend of the graph shows tripping current rose gradually with increasing value of THD. Graph for Figure 4 is made up by using minitab software. The gradient for the graph is 0.003190 . The gradient from the graph can be obtained by using formula in Equation 1:

$$
\text { Gradient of graph }=\frac{y_{2}-y_{1}}{x_{1}-x_{2}}
$$

Therefore, equation for graph on Figure 4:

$$
\begin{gathered}
y=a x+b \\
\text { Load current }(A)=0.9943+0.003190 \text { THD }(\%)
\end{gathered}
$$




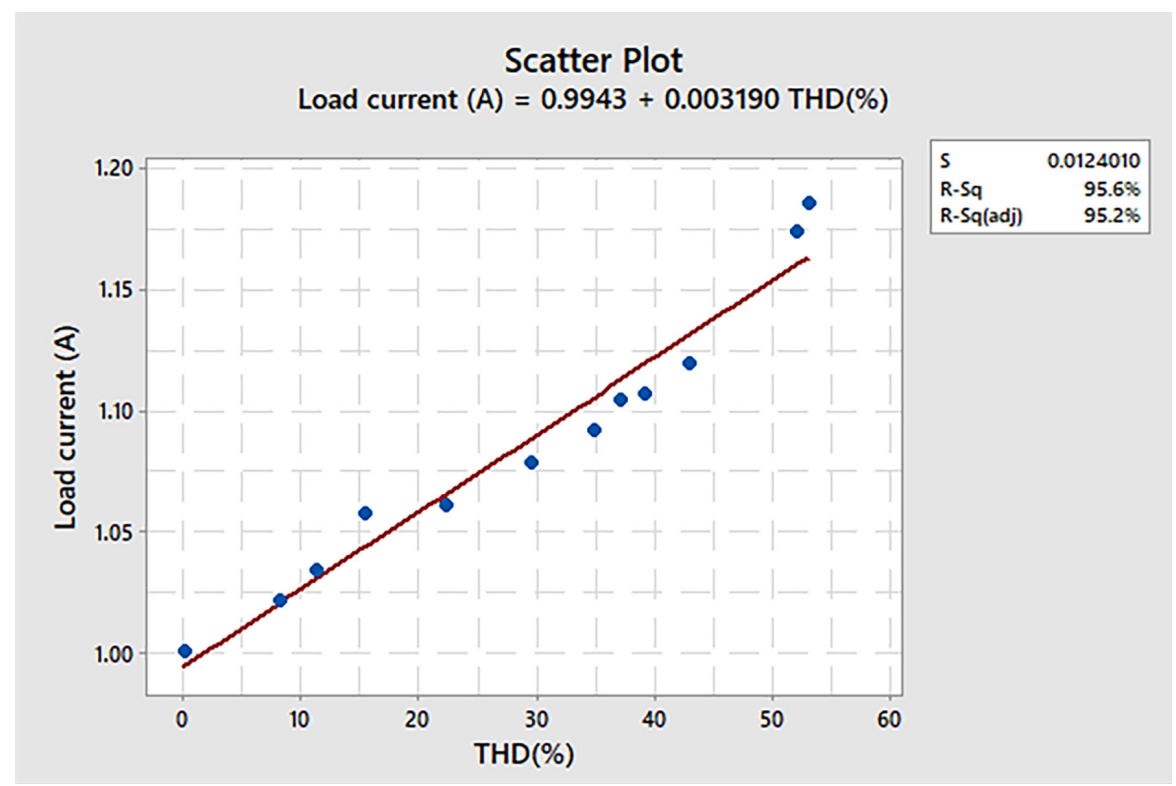

Figure 4: Graph load current vs THD.

The purpose of doing the scatter diagram is to find the correlation between two variables which in this case are tripping curent that are measured from load current and the different value of THD. The correlation calculation can be done by using the formula as in Equation 4:

$$
\mathrm{r}_{\mathrm{xy}}=\frac{\sum_{i=1}^{\mathrm{n}}\left(\mathrm{x}_{i}-\overline{\mathrm{x}}\right)\left(\mathrm{y}_{i}-\overline{\mathrm{y}}\right)}{\sqrt{\sum_{i=1}^{\mathrm{n}}\left(\mathrm{x}_{i}-\overline{\mathrm{x}}\right)^{2} \sum_{i=1}^{\mathrm{n}}\left(\mathrm{y}_{i}-\overline{\mathrm{y}}\right)^{2}}}
$$

where:

$\mathrm{r}_{\mathrm{xy}}=$ correlation between $\mathrm{x}$-axis and $\mathrm{y}$-axis

$\mathrm{n} \quad=$ number of sample

$\overline{\mathrm{x}}, \overline{\mathrm{y}}=$ mean values

Based on this equation, calculation of correlation can be done by inserting all the parameters mentioned above. For this project, our value for $n=12$, mean (x) is the THD and lastly, the mean (y) is the average rating for load current which consider as tripping current. The final value of the correlation, $\mathrm{r}_{\mathrm{xy}}$ is 0.978 . 
The correlation is strong. Even though the correlation is not a perfect positive correlation but in general, perfomance of overcurrent relay on power system has highly impact on THD.

Figure 4 is created from Table 1 . The result show different value of THD give a different impact to overcurrent relay. As can be seen here, the setting current to trip is $1 \mathrm{~A}$, but only $0 \%$ THD obey the current setting. The tripping current increase when the value of THD increase. This is due to current waveforms from non-linear loads appear distorted because of the non-linear waveform resulting from the addition of harmonics components to the fundamental current.

Based on Figure 4, the graph show when the higher value of THD, the value of tripping current also will increase due to impact of harmonic. In this experiment, when current setting is $1 \mathrm{~A}$, the fundamental current is also $1 \mathrm{~A}$. THD can be calculated by using Equations 5 and 6 :

$$
\begin{aligned}
& \mathrm{THD}=\frac{\mathrm{I}_{\mathrm{rms}}}{\mathrm{I}_{1, \mathrm{rms}}}=\sqrt{\sum_{\mathrm{h}=2,3, \ldots}\left(\frac{\mathrm{I}_{\mathrm{h}, \mathrm{rms}}}{\mathrm{I}_{1, \mathrm{rms}}}\right)^{2}} \\
& \mathrm{THD}=\frac{\mathrm{I}_{\mathrm{rms}}}{\mathrm{I}_{1, \mathrm{rms}}} \times 100
\end{aligned}
$$

The result from Table 1 for the higher value of THD shows that the tripping current will also increase as we can see from the formula in Equation 7:

$$
\mathrm{I}_{\text {rms }}=\mathrm{I}_{\text {fundamental }}+\mathrm{I}_{\text {harmonic }}
$$

Based on graph in Figure 4, when linear load are used, the tripping current is $1 \mathrm{~A}$. This is because the current supply is the fundamental current without include including the harmonic as shown in Equations 8 and 9:

$$
\begin{aligned}
\mathrm{I}_{\mathrm{rms}} & =I_{\text {fundamental }}+\mathrm{I}_{\text {harmonic }} \\
\text { Since } \mathrm{I}_{\text {harmonic }} & =0 \\
\mathrm{I}_{\text {rms }} & =I_{\text {fundamental }}
\end{aligned}
$$

For $8.1 \%$ THD the current start to trip when $1.021 \mathrm{~A}$. This is because of the total current at $1 \mathrm{~A}$, the fundamental current has not yet reached $1 \mathrm{~A}$. The result also has been influenced by harmonic current which consist $8.1 \%$ of THD. When THD increase up to $53.9 \%$ the tripping current start to trip at $1.185 \mathrm{~A}$ due to increase in total harmonic current and therefore increase the value of tripping current. 


\section{CONCLUSION}

The effect of current harmonic on overcurrent relay had successfully been investigated. Result had been obtained from the experiment and the equation had been made from the graph on Figure 4. Based on Equation 3, it can be concluded that, the result shows the tripping load current will increase when the THD increase. Correlation between tripping load current and THD is 0.978 . The correlation is strong eventhough is not a perfect positive correlattion in general. The overcurrent relay performance will be significantly affected and a malfunction will incur due to effect of harmonic. The overcurrent relay will not able to isolate the faulty location as they will trip in an undesired way when a fault occurs in the system. Different values of THDs are presented and analysed to compare overcurrent relay impact towards harmonic and also towards the overall power system. For example, at $0 \%$ THD the tripping load current trip on its setting limit, while when harmonic was injected the performance of overcurrent relay getting worse. The result conclude that in lower value of harmonic, it has better reliability benefits to the power system. In conclusion, impact of harmonic on the overcurrent relay is successfully analysed and presented to provide valuable information on potential benefits of the system. For future work, research on overcurrent relay can be further developed considering to reduce harmonics and also increase the diameter of cable. The idea is to optimise ovecurrent relay usage while considering economical and protection aspects in power systems.

\section{ACKNOWLEDGEMENTS}

We would like to express our greatest appreciation to School of Electrical and Electronics Engineering, Universiti Sains Malaysia for supporting this work.

\section{REFERENCES}

1. Jos Arrillaga, J., Smith, B. C., Watson, N. R. \& Wood, A. R. (1997). Power system harmonic analysis. London: John Wiley and Sons Ltd., https://doi.org/10.1002/9781118878316.

2. Tin, H., Abu-Siada, A. \& Masoum, M. S. (2011). Impact of harmonics on the performance of over-current relays. In AUPEC 2011. Brisbane: Institute of Electrical and Electronics Engineers (IEEE).

3. Ukil, A., Deck, B. and Shah, V. H. (2010). Current-only directional overcurrent relay. IEEE Sens. J., 11(6), 1403-1404, https://doi.org/10 $.1109 /$ JSEN.2010.2094186. 
4. Sleva, A. F. (2010). Protective relay principles. Baco Raton, London, New York: Taylor and Francis Group.

5. Verma, H. K. \& Rao, T. S. M. (1976). Inverse time overcurrent relays using linear components. IEEE Trans. Power Appar. Syst., 95(5), 17381743, https://doi.org/10.1109/T-PAS.1976.32273.

6. Wannous, P. T. K. \& Toman P. (2016). The effects of harmonics on overcurrent relays. 201617 th international scientific conference on electric power engineering (EPE). Prague: IEEE, 1-6, https://doi.org/10.1109/ EPE.2016.7521794.

7. Han, J., von Jouanne, A. \& Temes, G. C. (2006). A new approach to reducing output ripple in switched-capacitor-based step-down DC-DC converters. IEEE Trans. Power Electron., 21(6), 1548-1555, https://doi. org/10.1109/TPEL.2006.882973.

8. Etezadi-Amoli, T. F. M. \& Florence, T. (1990). Voltage and current harmonic content of a utility system: A summary of 1120 test measurements. IEEE Trans. Power Delivery, 5(3), 1552-1557, https://doi. org/10.1109/61.58000.

9. StudyElectrical.com (2016). Relay timing characteristics: Instantaneous, inverse time and definite time lag relays, 14 November. Retrieved from http://www.studyelectrical.com/2017/01/relay-timing-characteristicsinstantaneous-inverse-time-definite-time-lag-relays.html

10. ELSebaay, A., Ramadan, M. \& Adma, M. A. A. (2017). Studying the effect of non-linear loads harmonics on electric generator power rating selection. Eur. Sci. J., 13(18), 548-561, https://doi.org/10.19044/esj.2017. v13n18p548.

11. Ajenikoko, G. A. \& Ojerinde, A. I. (2015). Effects of total harmonic distortion on power system equipment. Innovative Systems Design and Engineering, 6(5), 114-120.

12. Zellagui, M., Benabid, R., Chaghi, A. \& Boudour, M. (2015). Impact studies of total harmonic distortion on directional overcurrent relay performance. Sci. Bull. C Electr. Eng. Comput. Sci., 77(4), 359-372.

13. Contractor, J., Kapil, P. N. \& Shah, B. (2015). Harmonic mitigation for power quality improvement. Int. J. Res. Eng. Technol., 4(5), 5-12, https://doi.org/10.15623/ijret.2015.0405002. 